mortality from all causes and from all medical causes (excluding trauma) than did DZ twins.

Using life-table methods, survival ( $I_{\mathbf{x}}$ ) functions have been computed from the accumulated data that estimate the probability of living to a specific age for the twins surviving their brothers death. These functions have been compared between $\mathrm{MZ}$ and $\mathrm{DZ}$ twins and a somewhat greater mortality was found among the MZ twins. For all MZ twins, the probability of living to a specific age was comparable to that of the $\mathrm{DZ}$ twins.

The various measures of concordance for early total mortality and for early mortality from medical causes provide various evaluations of the genetic determination of these events.

Dr. Zdenek Hrubec, Department of Environmental Hygiene, The Karolinska Institute, S-104 or Stockholm 60, Sweden

TWIN CONCORDANCES IN SWEDEN FOR MORTALITY AND THEIR VARIATION WITH ZYGOSITY

ZDENEK HRUBEC, ULLA LORICH, ULF DE FAIRE, TORBJÖRN LUNDMAN

Department of Environmental Hygiene, The Karolinska Institute, Stockholm, Sweden

Medical Department, Serafimer Hospital, Stockholm, Sweden

The Twin Registry of the Karolinska Institute in Stockholm consists of 9680 male and 12210 female individuals, identified as same-sex twins from birth certificates for the years 1886 to 1925 , and replying to a questionnaire in 1961 . These twins are being followed for mortality through the Swedish Central Bureau of Statistics and through questionnaire mailings. In June I 972 there were 134 I deaths among the males and 1269 deaths among the females. There were, respectively for males and females, 237 and 199 twin pairs with both members deceased. Only 92.9 and 65.9 such pairs would be expected respectively among the males and the females in the Registry under the hypothesis of no association of death within pairs.

Using the questionnaire responses it has been possible to classify the concordantly deceased twins as $\mathrm{MZ}$ and as DZ. Differences in mortality concordance between the two zygosity groups are evaluated using intrapair correlations of age at death and concordance rates for deaths from different causes.

Various cause-of-death groups appear to have different degrees of genetic determination. While the extent of apparent genetic determination depends on the measures of concordance used, the relative ranking of different diseases seems fairly consistent.

Dr. Zdenek Hrubec, Department of Environmental Hygiene, The Karolinska Institute, S-I O4 o I Stockholm 6o, Sweden

\section{TECHNIQUES AND PROBLEMS \\ OF DYNAMIG FEATURES \\ IDENTIFICATION IN HUMAN \\ POPULATION PARAMETERS \\ WITH A SPEGIAL REFERENCE \\ TO THE SERIAL ANALYSIS \\ OF INFAN'T MORTALITY}

\section{ANTONIO BELLACICCO}

Department of Statistics, University of Rome, Italy

As a general rule, we have to distinguish between observational data and experimental data. As a consequence, we have to distinguish among the various techniques to be used in the analysis of a given phenomenon.

In the same way, we distinguish between instantaneous and dynamic phenomena.

Chronogenetics concerns the temporal evolution of hereditary parameters. Generally speaking, there are phenomena, like mortality, which can be analysed either through special stochastic models, like Poisson processes, particularly suitable for experimental data, or through the approximation of "given "data by dynamic models and analysis of basic hidden characteristics, like principal cycles.

As an example of the latter approach, infant mortality can be studied in a dynamic way through spectral-analysis techniques. This approach can help the researcher in building up suitable models of the evolution of some basic characteristics in a population. Moreover, it is possible to detect the environmental influence and therefore to 
isolate the true genetic ground of the phenomenon.

An account is given of basic techniques in time-series analysis, and results obtained in the field of infant mortality in Italy are discussed.

Dr. A. Bellacicco, Istituto di Statistica dell'Università di Roma, Italy

\section{GHRONOGENETICS OF MUSCULAR DYSTROPHY}

\author{
G. DEL PORTO, E. D'ALESSANDRO, \\ G. BRENCI
}

Department of Medical Genetics, University School of Medicine, L'Aquila, Italy

The Gregor Mendel Institute of Medical Genetics and Twin Research, Rome, Italy

A genealogical study has been carried out in the families of subjects affected by progressive muscular dystrophy.

The following parameters have been taken into account: (I) the age of onset, (2) the clinical characteristics, and (3) the age of the possible exitus.

Consanguineous series, with their genetic correlation, are drawn from this sample of families, and $r$ correlation coefficients are calculated with respect to the above experimental parameters. The $r$ values thus obtained are then compared with those that one would expect on the hypothesis that the temporal traits considered be genetically determined.

Prof. G. Del Porto, Cattedra di Genetica Medica, Università dell'Aquila, Italy

\section{A CHRONOGENETIC APPROAGH TO PSORIASIS}

\section{R. GAVALIERI, G. ORSI, S. ZECCA, M. ROMANO}

The Immacolata Institute of Dermatology (IDI), Rome, Italy

Psoriasis is a genetically conditioned dermatological disease characterized by significantly different sex and age distributions. It could thus be the object of a chronoge- netic analysis, using the age of onset as a genetically determined and quantitative phenotypic parameter.

A total of 2000 index cases has been considered and their families analyzed with respect to the segregation ratios in the sibships of the subjects and in those of their parents. The observed values of segregation are found to be not significantly different from those expected under the hypothesis of a diallelic monomeric autosomic trait.

It is concluded that the temporal trait, age of onset, must be genetically conditioned and that its chronogenetic variability determined by the genetic variability of the starting ergons - may be assessed by means of standard techniques for quantitative analysis.

Prof. R. Cavalieri, Istituto Dermopatico dell'Immacolata, Via dei Monti di Creta 104, oo 67 Roma, Italy

\section{WILSON'S DISEASE AND MENKES' DISEASE-A CONTRAST IN GHRONOGENETICS}

SEAN O'REILLY, ANATOLE S. DEKABAN, ROGER AAMODT, WARREN F. RUMBLE, GERALD S. JOHNSTON

Department of Neurology, The George Washington University Medical School, Washington, D.C., USA

Developmental and Metabolic Neurology Branch, NINDS, and Nuclear Medicine Department, NIH, Bethesda, Maryland, USA

In discussing the "timing" of hereditary diseases in their book Cronogenetica: l'Eredità del Tempo Biologico, Gedda and Brenci point out the limitations of the traditional classification of abnormal genes into lethal and sublethal categories.

The diseases with which this paper is concerned provide a striking confirmation of such limitation, in their clinical and metabolic aspects. Both diseases can be characterised by the disorders of the physiology of copper, an essential trace-element, which they display.

In Wilson's disease the patho-physiology is one of copper-toxicity associated with failure of biliary excretion of copper and its accumulation in various organs.

In Menkes' disease the problem is related to defective gastro-intestinal absorption of copper and the pathologic lesions are for the 